\title{
Perspectivas de autoria em práticas de APP-Learning
}

\author{
Wallace Almeida \\ Edméa Santos
}

\section{Resumo}

Este artigo surge a partir do levantamento dos achados de uma pesquisaformação na cibercultura, onde buscamos compreender, como mobilizar Atos de Currículo que contemplassem a proposta de App-Learning. Nossa opção metodológica foi a pesquisa- formação na cibercultura (SANTOS), a multirreferencialidade (ARDOINO) e as pesquisas nos/dos/com os cotidianos (CERTEAU, ALVES). Como achados da pesquisa apresentamos as narrativas e imagens, além da minha própria experiência, transformação e aprendizado fruto dessa convivência entre praticantes, pesquisadores e artefatos tecnológicos. Verificamos também a manifestação da autoria dos praticantes em App-Learning na produção de um recurso didático estruturado por uma aplicação de Realidade Aumentada na Aula 1, que surge a partir dos saberes coletivos em contexto colaborativo de aprendizagem e mediação.

Palavras-chave: Pesquisa-formação na cibercultura. Docência Online. Cotidianos. Formação de Professores. Ensino Superior, App-Learning, Atos de Currículo.

\section{Author Perspectives on APP-Learning practices}

\section{Abstract}

This article arises from the survey of the findings of a research-training in cyberculture, where we seek to understand, how to mobilize Curriculum Acts that contemplate the App-Learning proposal. Our methodological option was the research-training in cyberculture (SANTOS), the multireferentiality (ARDOINO) and the researches in / with / to the daily ones (CERTEAU, ALVES). As findings of the research we present the narratives and images, besides my own experience, transformation and learning result of this coexistence between practitioners, researchers and technological artifacts. We also verified the manifestation of App-Learning practitioners in the production of a didactic resource structured by 
an Augmented Reality application in Class 1, which arises from collective knowledge in a collaborative context of learning and mediation.

Keywords: Research-training in cyberculture. Teaching Online. Everyday. Teacher training. Higher Education, App-Learning, Curriculum Acts.

\section{Perspectivas del autor en APP-Aprendizaje de prácticas.}

\section{Resumen}

Este artículo surge a partir del levantamiento de los hallazgos de una investigación-formación en la cibercultura, donde buscamos comprender, cómo movilizar Actos de Currículo que contemplasen la propuesta de App-Learning. Nuestra opción metodológica fue la investigación-formación en la cibercultura (SANTOS), la multirreferencialidad (ARDOINO) y las investigaciones en los / as / con los cotidianos (CERTEAU, ALVES). Como hallazgos de la investigación presentamos las narrativas e imágenes, además de mi propia experiencia, transformación y aprendizaje fruto de esa convivencia entre practicantes, investigadores y artefactos tecnológicos. También verificamos la manifestación de la autoría de los practicantes en App-Learning en la producción de un recurso didáctico estructurado por una aplicación, que surge a partir de uno contexto colaborativo de aprendizaje y mediación.

Palabras clave: Investigación-formación en la cibercultura. Docencia en línea. Todos los días. Formación de profesores. Enseñanza Superior, App -Learning, Actos de Currículo.

\section{Introdução}

Tratamos aqui da mobilização de Atos de Currículo na Perspectiva de App Learning em sintonia com os docentes em formação do curso de Pedagogia a distância da UERJ, percebendo o surgimento do processo de autoria na produção de interações formativas na interface cidade/ciberespaço. Posicionamos a perspectiva de App -Learning (SANTAELLA, 2016) em consonância com as interações proporcionadas pela ótica da Realidade Aumentada na intenção de tecer uma prática formativa inspirada nos usos da Cibercultura.

A cibercultura é a cultura contemporânea que revoluciona a comunicação, a produção e circulação em rede de informações e conhecimentos na interface cidade/ciberespaço (SANTOS, 2014, 
pg. 9-10) e nasce da totalização de nossas técnicas, práticas, de modos de pensamento e de valores que se desenvolvem em consonância com a eclosão da rede.

Em seu atual contexto, a cibercultura ganha os ares da mobilidade na incorporação dos dispositivos móveis no cotidiano social, na consolidação das práticas e vivências que emergem dos agrupamentos sociais conectados revelando novas oportunidades e formas de atuação como veremos a seguir.

O smartphone se torna assim o bub desse cenário tecnológico social. É através dele que baixamos os Apps que nos permitem interagir com nossos colegas de trabalho, familiares e amigos, como também nos movemos por uma multiplicidade de espaços formativos, convertendo-se portanto em um bem essencial a cada indivíduo que constitui a partir dos seus usos, e influenciado pela cultura que o permeia, um dispositivo tão complexo como o próprio indivíduo que dele faz uso.

Essa pesquisa nasce do contexto das investigações do GPDOC - Grupo de Pesquisa Docência e Cibercultura, coordenado pela Profa. Dra Edméa Oliveira dos Santos, e tem como mote a investigação minuciosa desse fenômeno, a saber: a Pesquisa-Formação na Cibercultura sob a ótica do App-Learning, onde buscamos compreender, em conjunto com os praticantes ${ }^{1}$ como essa nova forma de aprendizagem, tão em voga em nosso cotidiano, pode nos motivar a viver, sentir produzir e transformar efetivamente a nossa prática docente em direção ao movimento de um novo fazer pedagógico.

Nesse sentido, nos cercamos de todas as experiências vividas e narradas onde agora, no findar de uma pesquisa de mestrado, fazemos um recorte dos achados buscando revelar como se dá o processo de autoria In-App. Dispomos também os momentos e movimentos da pesquisa, apresentando, em primeiro lugar, aos

Pesquisamos na cibercultura atuando como praticantes culturais (CERTEAU,1994) produzindo dados em rede, concebemos os sujeitos da pesquisa não como meros informantes, mas sim como são praticantes culturais que produzem culturas, saberes e conhecimentos no contexto da pesquisa (SANTOS, 2014). 
praticantes o conceito de App-Learning e em seguida proporcionando contextos que pudessem mobilizar saberes necessários para a formação de sujeitos de autoria em App-Learning, mediante a convivência na cibercultura e nas práticas intencionais que desenvolvemos em situações de ensinoaprendiragem.

A pesquisa foi desenvolvida no âmbito da disciplina Informática na Educação, do curso de Pedagogia a distância da UERJ, oferecida em parceria com a Fundação Centro de Ciências e Educação Superior a Distância do Estado do Rio de Janeiro (Cecierj) / Consórcio CEDERJ em todos os pólos que hoje são atendidos pela tutoria do curso, sendo compreendidos pelos municípios de Angra dos Reis, Belford Roxo, Itaguaí, Magé, Nova Friburgo, Nova Iguaçu, Paracambi, Petrópolis, Resende, Rocinha, São Pedro e Três Rios.

A disciplina conta com um grupo no Facebook e está situada na plataforma Moodle, que é a principal plataforma de aprendizagem para a prática de educação online onde os alunos e os docentes estão em um contexto geograficamente disperso.

Nesses espaços mobilizamos Atos de Currículo na perspectiva de App-Learning e vivemos em prática o desafio de ser um docente na cibercultura, aplicado a nossa própria experiência como praticante cultural e dialogando com os outros praticantes da disciplina "Informática na Educação" no curso de Pedagogia a distância da UERJ, nos autorizando nos usos dos aplicativos e nas práticas educativas, incorporamos a linguagem e as particularidades das mídias para mobilizar saberes necessários para o surgimento da autoria, um mergulho radical e provocante que se descreve a seguir.

\section{In-App Autoria - Perspectivas de Autoria em App-Learning}

A construção do autor é uma função não apenas do discurso, mas também de uma materialidade, materialidade e discurso que na minha perspectiva de análise são indissociáveis Roger Chartier ${ }^{2}$

CHARTIER, R. O Que é um Autor? Revisão de uma Genealogia. São Carlos: EDUFSCar, 2012. p. 62-63. 
O entendimento do papel da autoria nas questões que envolvem o processo de pesquisa de práticas de ensinoaprendizagem se torna fundamental na sociedade contemporânea. Com o surgimento da Web surgem também novas concepções do verdadeiro papel de autor, que deixa a imagem de figura individual e solitária enclausurada que remonta ao início do século XIX e passa a se aproximar da contemplação da efervescência do compartilhamento e colaboração dos indivíduos.

As possibilidades agora se tornam infinitas à medida que é também infinito o ciberespaço. A maneira como interagimos e buscamos as informações em nosso cotidiano foram completamente transformadas pela perspectiva da mobilidade e dos aplicativos, que através de uma assinatura mensal, permitem que se tenha acesso ilimitado a conteúdo multimídia de autoria diversa da forma mais simplificada possível. Podemos assistir um documentário no $\mathrm{Ne}$ tflix, escutar uma música ou acompanhar um podcast no Spotify, ler sem limites no Kindle e experimentar vários universos de gameplay através do Xbox Game Pass. Esse cenário de facilidade de acesso e de não pertencimento dos conteúdos cria novas perspectivas de interação do homem com a informação. Antes tínhamos a prática de baixar tudo o que estava disponível na internet, muitas vezes de forma informal ou ilegal, para nos tornarmos "proprietários" daquele conteúdo. Comprávamos CDs, DVDs e até mesmo alguns Blu-rays em busca de entesourar e preservar aquilo que nos importava e não gostaríamos de perder.

A Internet não deve servir apenas para saquear os conteúdos, até pode ser utilizada como interface de pesquisa. Mas ressalto que a rede é uma incubadora de mídias que permite produzir, disponibilizar e compartilhar conteúdos em ambientes virtuais de aprendizagem por meio de imagens e gráficos, enfim, das mais variadas maneiras (SANTOS, 2018)

Porém com o surgimento dos serviços de assinatura e de streaming, passamos a vislumbrar um novo cenário que iria prover alternativas a esse processo. Agora se pode ter acesso ilimitado ao 
acervo do serviço, e por razoável quantia mensal, consumirmos como e onde quisermos o conteúdo. Essa premissa ajudou e muito a mudar o cenário de pirataria e ilegalidade na medida que era muito mais prático pagar um valor mensal e ter acesso a quase tudo o que se quer ver/ler/ouvir do que procurar em sites e fóruns obscuros na internet, muitas vezes lotados de vírus e pornografia, pelo mesmo conteúdo. No fim a praticidade venceu a gratuidade.

Porém quando tratamos de ciência, a política da autoria é permeada por uma série de particularidades que não existem ou não são tão importantes em tantas outras formas de manifestação cultural.

O motivo está no papel que o reconhecimento da autoria desempenha na ciência (certificação do conhecimento) e na vida do pesquisador: mais do que o lucro financeiro, está em jogo o seu nome. Para entendermos o quanto o prestígio do nome significa para um pesquisador, poderíamos fazer uma analogia com o que a credibilidade da moeda representa para a economia de uma nação, ou os bens pessoais para um indivíduo. Assim, é essencial para a sobrevivência profissional de um pesquisador ter a autoria de suas produções científica validada e reconhecida pelos pares. $\mathrm{O}$ reconhecimento do valor da contribuição científica se dá com a publicação e se firma pela citação ao texto publicado por outros pesquisadores. (MIRANDA, SIMEÃO E MUELLER, 2007, pg. 40)

Essa perspectiva restrita e engendrada da atuação da autoria na ciência pode ser alternada e renovada com a prática de compartilhamento e do uso da criatividade e do conhecimento através de licenças jurídicas gratuitas, como é o caso da Creative Commons, que é uma organização sem fins lucrativos que fornecem uma maneira simples e padronizada para dar ao público permissão para compartilhar e utilizar o seu trabalho criativo, sob condições de sua escolha.

As licenças Creative Commons não são contrárias aos direitos de autor. Elas funcionam complementarmente aos direitos autorais e permitem que você modifique seus termos de direitos autorais para melhor atender às suas necessidades. (CREATIVE COMMONS, 2018) 
Essa alternativa, embora não resolva por si mesma a questão do lucro financeiro que está atrelado a imagem do copyright ${ }^{3}$, proporciona sob a égide de uma filosofia copyleft ${ }^{4}$, um campo muito maior de interação, de reconhecimento e de validação de sua produção pelos pares e através de uma política mais branda de publicação e compartilhamento. Interações e compartilhamentos esses, que são fundamentais para a produção daquilo que veio a se chamar de autoria coletiva.

A partir do final dos anos 90 e do início do novo século as comunidades virtuais experimentaram evolução exponencial, apoiadas em plataformas abertas - tanto no que concerne aos códigos como a conteúdos, permitindo a autoria coletiva e cooperativa, através de diferentes estruturas como, por exemplo as wiki - sites que permitem ao usuário agregar ou editar informação. $\mathrm{O}$ termo open content - conteúdo aberto - origina-se por similaridade a open source - código aberto e descreve qualquer tipo de trabalho criativo incluindo artigos, imagens, áudio e vídeo que é publicado em um formato que, explicitamente, permite sua reprodução. Tecnicamente constitui um arquivo compartilhado que pode ser livremente re- utilizado. Os conteúdos podem estar em domínio público ou sob uma licença do tipo GNU Free Documentation License. (PASSARELLI, 2007, pg. 114, grifo nosso)

A autoria coletiva surge portanto da interação entre indivíduos singulares, que em perspectiva de conectividade em rede, tro-

3 O Copyright proíbe a execução de uma parte da obra ou ela no todo, por terceiros não autorizados. Ao atribuir a licença Copyright, significa que o autor tem todos os direitos reservados sobre a sua obra. É uma licença fechada. Não permite modificação, alteração, distribuição e nem criação de obra derivada, sem permissão do autor. No Copyright, o autor pode permitir o uso de informações, para o uso individual ou pessoal. Mas proíbe a distribuição de sua obra. Fonte: http://bit.ly/copyrile

$4 \quad$ O Copyleft surgiu para ser aplicado à documentação do software livre, mas pode ser também aplicável a qualquer tipo de documento ou obra. O Copyleft visa estabelecer o direito de copiar e redistribuir um trabalho determinado. Significa "direito de cópia”. O Copyleft permite a livre circulação da obra intelectual e visa favorecer a expansão do conhecimento. Este tipo de licença permite a livre modificação e distribuição de determinada obra, seja para fins lucrativos ou não. Fonte: http://bit.ly/copyrile 
cam entre si e com o mundo através de experiências significativas, deixando para trás o simbolismo e o significado da autoria como um exercício individual e ao aproximar-se cada vez mais de seus pares perde suas limitações e fronteiras em pervasividade na construção de um novo ser coletivo e pensante cuja mensagem é aquela que é compartilhada por todos.

Atualmente, humanos e objetos estão cada vez mais pervasivos, em constante fusão e comunicação recursiva, em que os objetos nos levam a agir, e vice-versa, de acordo com nossas necessidades (LEMOS, 2013). Assim, de acordo com Latour (2012), as relações produzidas nesses movimentos de humanos e não humanos e tecidas nas associações dão sentido à rede. O sentido rede não está ligado à infraestrutura e sim a um conceito dinâmico. Ela não é o que conecta, mas é o que gera associações, que forma o social. Quando o autor fala em rede, se refere também a ator, ou seja, à relação ator-rede, pois este gera, produz ação e movimento. (SANTOS, PONTE \& ROSSINI, 2015, pg. 518, grifo nosso)

Segundo os autores, o produto dessas relações estabelecidas entre os interlocutores é que vão emergir a verificação de autoria e mobilizar novas oportunidades de sua efetivação e de diversos outros sentidos que venham a ser acoplados na produção inicial.

Assim, a autoria se constitui enquanto processo complexo - desencadeada pelas perturbações e diferenças - e recursivo, em relação a rede de convivência. Portanto, transcende à idéia de produtor de uma obra, no sentido de que a autoria se efetiva na relação com o outro. $\mathbf{O}$ autor não se produz sozinho, mas por meio da tríade autor-obra-outro. (BACKES, 2012, pg. 74, grifo nosso)

É preciso portanto garantirmos que exista lugar para o choque, a perturbação e a diferença entre discursos e as relações dialógicas entre os interlocutores e os praticantes para que possamos efetivar o meio propício para o surgimento da autoria. Esse é um fundamento que muitas vezes deixamos passar quando, em nossas práticas educativas, efetivamos a preposição e a perpetuação do monólogo como forma de repasse de informação e de conhe- 
cimento em sala de aula. Demandamos atenção, ordenamos que se sentem e impomos o silêncio enquanto o eu, a autoridade e a sapiência em pessoa, em sua infinita misericórdia, desvela os mais ocultos mistérios da humanidade e do cosmo.

Como poderia eu, imaginar ou mesmo conceber, que aquilo que estou falando pode ser muitas vezes rebatido, corrigido e atualizado por aquele, que é sujeito do meu saber? Como posso eu assentir que aquele aluno, uma criatura "sem luz", possa saber mais do que eu ou possa até mesmo tomar o meu lugar?

Essa linha de pensamento que oprime, congela e retém e garante ao professor o privilégio e a exclusividade do discurso é o que perpetua a alienação do aluno pela escola e pela sociedade em via de garantir que cada um permaneça no seu lugar, sem nunca ousar se posicionar, agir ou reagir a qualquer forma de opressão.

Mas esse cenário tenebroso tem sido destituído em massa nas práticas inovadoras da educação online, que vem intervindo e atuando de forma revolucionária na perspectiva de garantir a visão de que não tenhamos mais uma relação baseada em emissão e recepção, de um para todos, mas sim de todos para com todos e em todos os espaços onde se efetiva o cotidiano de interações entre praticantes da cibercultura. Sejam esses os espaços tradicionais das salas de aula, os fóruns de discussão dos ambientes virtuais de aprendizagem como o Moodle ou até mesmo os aplicativos de dispositivos móveis onde possam se efetuar experiências de aprendizagem e formação.

É nesse cenário complexo e dinâmico que surge a educação online como um fenômeno da cibercultura (SANTOS, 2010). A educação online não é uma evolução da educação a distância, mas sim "um conjunto de ações de ensino e aprendizagem ou atos de currículo mediados por interfaces digitais que potencializam práticas comunicacionais interativas e hipertextuais" (SANTOS,

2010, p. 37). A modalidade da educação a distância tem como princípio a lógica comunicacional das mídias de massa (impressos, televisão e rádio), ou seja, a transmissão e a recepção de conteúdos estáticos e fechados, impossibilitando a participação dos praticantes culturais na produção e 
atualização desses conteúdos. Já a educação online tem um grande potencial comunicacional e pedagógico quando interfaces colaborativas da Web 2.0 são articuladas a uma mediação docente intensa e provocadora. Para isso, o professor precisa conhecer as funcionalidades dessas interfaces para que possa explorá-las de acordo com suas necessidades. (SANTOS, PONTE \& ROSSINI, 2015, pg. 520, grifo nosso)

Como o nosso objetivo de pesquisa era proporcionar, através da efetiva proposição de atos de currículo, contextos que pudessem formar a nós mesmos e aos nossos praticantes como sujeitos de autoria em App-Learning ante a convivência na cibercultura, tivemos a necessidade de produzir um desenho didático que nos proporcionasse livre articulação entre os conteúdos teóricos escolhidos, os aplicativos móveis percebidos e a criação de um canal livre de interação, compartilhamento e partilha de ideias e sentidos para potencializar a questão da hipertextualidade e a possibilidade de recombinação, mixagem e reapropriação de nossos sentidos em nossas produções em um momento coletivo de autoria e autorização próprias de uma pesquisa-formação na cibercultura.

Na pesquisa-formação, o docente constrói, juntamente com os participantes, dispositivos formativos visando à produção de conhecimentos e à reestruturação de sua prática (NÓVOA, 2004). Esses dispositivos são, na verdade, táticas (CERTEAU, 1994) singulares que os sujeitos utilizam nos cotidianos para lidar com os dilemas vivenciados em sua docência. Os acasos revelam novas dimensões problemáticas, convidando todos a "pensar diferentemente", ou seja, livres de controle, classificação, distinção e comparação (CERTEAU, 2011). A curiosidade, o envolvimento emocional e a implicação são essenciais para a participação coletiva, propiciando a autonomia, a autoria, a troca de saberes e a interatividade (SILVA, 2010). Nesse sentido, professores e estudantes se tornam simultaneamente sujeitos e objetos da formação. (SANTOS, PONTE \& ROSSINI, 2015, pg. 524, grifo nosso)

Desse modo, pudemos vivenciar, através da nossa experiência de pesquisa o surgimento da autoria entre os praticantes da dis- 
ciplina na realização das propostas estabelecidas para aquele semestre. Onde após vivenciarem uma situação extremamente conflitante ao serem desafiados a conhecer, experimentar e criar um contexto formativo a partir de um dispositivo que até então era novidade mesmo entre eles. Um projeto que não poderia ser concretizado sem a partilha de ideias, sentidos e diferenças entre os grupos.

Quando propusemos, na Aula 1 - Educando em nosso tempo, que se unissem em grupos para a escolha do local e elaboração do trabalho, tínhamos como intenção proporcionar essa experiência de choque de realidade entre os cursistas, onde cada um precisasse sair de sua zona de conforto e segurança proporcionada pelo distanciamento físico do curso "à distância” para atuar em perspectiva de presença potencial, característica da educação online, constante entre si e conosco.

Assim pudemos vivenciar e verificar em nossa pesquisa o processo do que Backes (2012) define como "o desenvolvimento do processo de autoria”. Que, segundo a autora, é possível ser evidenciado em três tipos bem específicos de sua manifestação em educadores em formação, sendo essas a pré-autoria, a autoria transformadora e a autoria criadora.

A pré-autoria está relacionada à necessidade de estar vinculado a um pensamento já legitimado na dinâmica de relações do grupo, configurando-se, portanto, pela relação de aproximação. Nesse sentido, evidenciamos uma pré- autoria, quando nos autorizamos a falar sobre a nossa concordância com relação ao que o outro produziu. É imprescindível ressaltar que não é uma cópia, mas uma espécie de releitura de uma obra. A pré-autoria está relacionada à expressão do pensamento em concordância, semelhança e aproximação, o que difere da coordenação do pensamento (BACKES, 2012, pg. 80, grifo nosso).

Um exemplo claro dessa lógica de autoria pode ser verificado em diversos trabalhos postados no grupo do Facebook da disciplina, onde dentre eles, destaco abaixo a produção das praticantes Monique Souza e Renata Millan. 
Figura 1 - Captura de um exemplo de pré-autoria encontrado no curso da pesquisa.

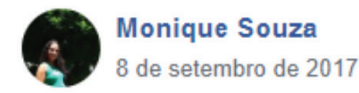

Utilizando o Aurasmas Tema para abordagem: Aurasma como recurso para alfabetização (associação de letras/palavras/figuras) Alunas: Monique Souza Matrícula: 16112080302 Renata Millan Matrícula: 16112080040

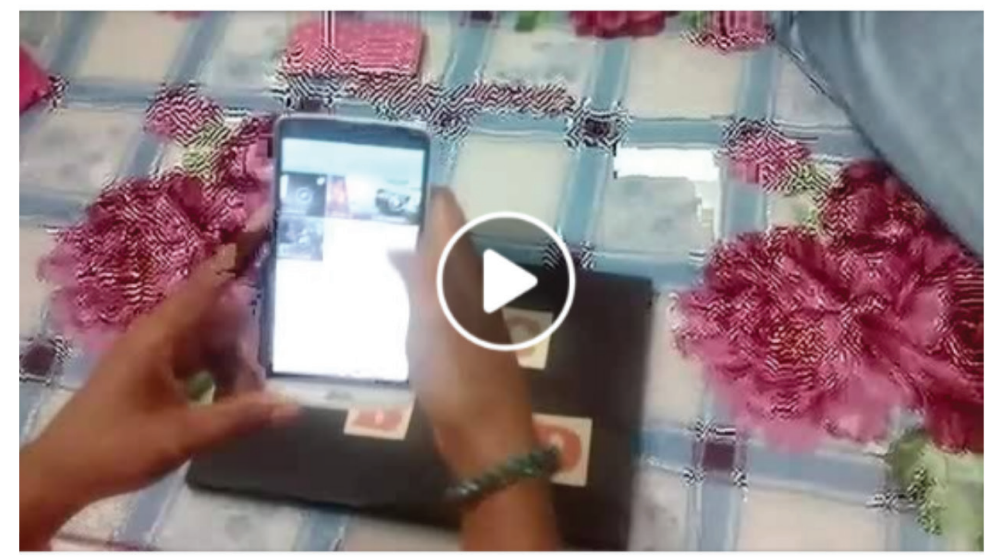

Sheila Albino e outras 5 pessoas

4 comentários Visualizado por 39

Wallace Almeida Muito interessante! Como foi a experiência de trabalhar com o aplicativo?

Curtir - Responder - 48 sem

Renata Millan Foi difícil rsrsrsrsrs. Associar um

conhecimento que não pertence ao nosso dia a dia, com práticas do cotidiano foi desafiador. Em parte devemos isto ao meu filho de 14 anos, que tem muito mais habilidade do que eu e Monique Souza juntas..... Por outro lado, urge a necessidade de trazer a tecnologia para a sala de aula. Se eu pudesse resumir em uma única palavra, diria que foi (e é!) DESAFIADOR.

Curtir - Responder - 48 sem

(b) 1

Fonte - Print do grupo do Facebook da disciplina 
O trabalho postado pelas cursistas abrangia a questão da alfabetização de alunos de uma turma de ensino fundamental, estabelecendo relações entre as letras, utilizando imagens, sons e vídeos que correspondessem aquela letra como sua inicial. Eu seu relato, Renata afirma que apesar das dificuldades do grupo em realizar o trabalho, elas conseguiram finalizar a atividade graças à ajuda que obtiveram de outro praticante, o seu filho de 14 anos, que possuía mais "habilidade" e conseguiu acionar as competências necessárias para fazer funcionar o aplicativo.

Apesar de ter sido uma produção autoral em sua execução e organização, a atividade proposta pelo grupo teve seu vínculo fixado em uma das práticas exemplificadas na "Live do Aurasma5", onde idealizo e produzo algo similar em um mesmo contexto educacional.

$\mathrm{Na}$ Live, vários cursistas perguntavam como poderíamos aplicar a realidade aumentada em um contexto educativo. Foi nessa ocasião que exemplifiquei alguns dos usos que eu mesmo fazia do mesmo, como professor de ensino fundamental. Dentre eles a atividade de estabelecer uma relação entre fonema e grafema na produção da consciência fonológica.

Ao apontar a câmera do smartphone para a imagem da letra a criança pode ver um pequeno vídeo mostrando como a letra é escrita ao mesmo tempo que pode ouvir o áudio de sua respectiva pronúncia.

Mesmo expressando a mesma premissa da atividade que eu já havia exemplificado, Monique e Renata expressaram sua própria versão daquilo que elas haviam compreendido, reforçando a utilidade e relevância da abordagem escolhida em um contexto real de alfabetização.

\footnotetext{
5 A Live do Aurasma ocorreu no dia 30 de agosto de 2017 e foi transmitida no grupo da disciplina no Facebook. Tivemos 40 pessoas acompanhando a transmissão ao vivo rendendo 69 comentários durante o evento. Trabalhamos cada etapa da atividade, iniciando pela concepção da ideia, a escolha do material, o funcionamento do aplicativo, a publicação da aura e a divulgação e a postagem final no Moodle. O conteúdo, depois de transmitido, gerou um vídeo gravado que ficou disponível no grupo para consultas futuras e gerou mais 171 visualizações pontuais após a sua transmissão inicial.
} 
Figura 2 - Captura do conceito explicado na live do Aurasma.
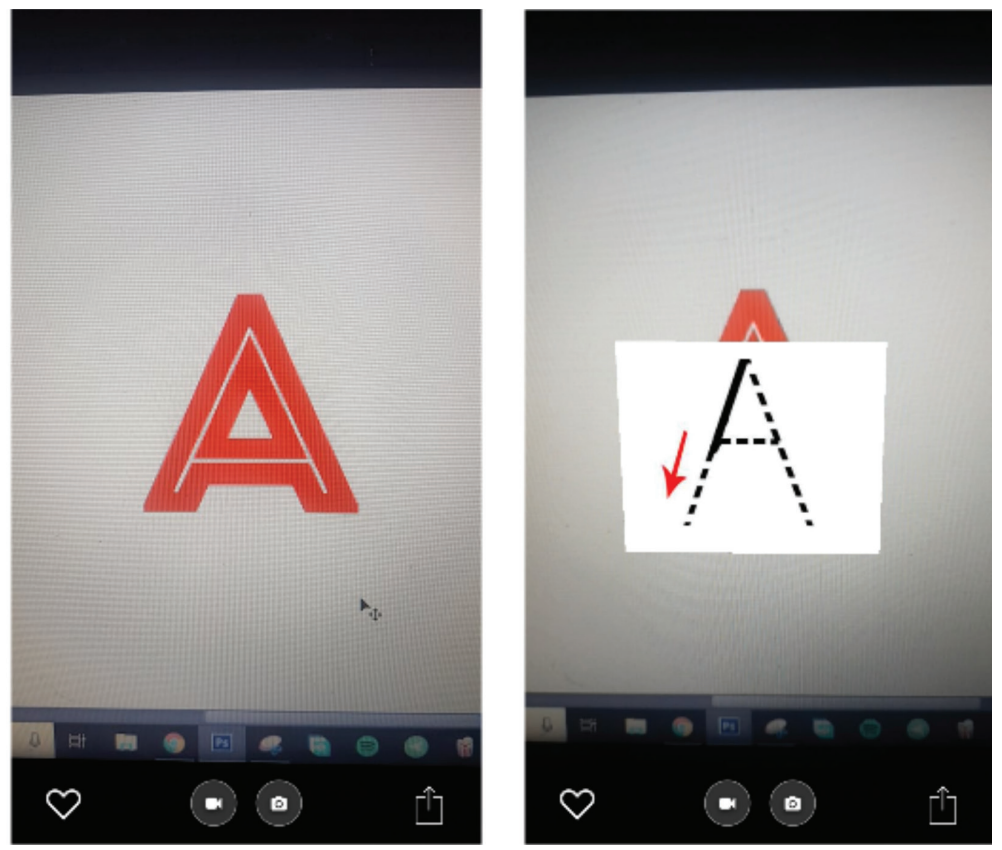

Fonte - Print de tela do smartphone do pesquisador

A segunda manifestação de autoria, a autoria transformadora, pode ser caracterizada pela ação que transcende uma ação já legitimada (BACKES, 2012, pg. 81) e pode ser exemplificada, no contexto de nossa pesquisa, na captura de trechos da conversa entre a praticante Débora Ricardo e os pesquisadores Wallace e Felipe.

A praticante Débora estava encontrando problemas para fazer funcionar o aplicativo de forma que atendesse a sua proposta, que seria de trabalhar a importância do turismo ecológico.

Ela tinha como premissa a utilização da Realidade Aumentada no âmbito escolar, trabalhando conteúdo da disciplina de geografia, na perspectiva do turismo ecológico tendo o foco na prática de Rafting no encontro entre os três rios muito conhecidos da região. Débora foi uma das primeiras praticantes a tentar a produção do conteúdo da aura em vídeo, argumentando inclusive o motivo 
de sua opção. Ela havia tentado fazer com que o aplicativo disparasse o vídeo que ela havia escolhido, mas mesmo após várias tentativas e de grande frustração ela não desistiu de sua ideia e buscou ajuda com os tutores da disciplina

O vídeo trata da questão do turismo ecológico e de como precisamos valorizar e exercer essa modalidade turística que busca conservar e promover o cuidado com o patrimônio natural através do desenvolvimento de uma consciência ambientalista. O problema é que o vídeo ficava travando, repetindo somente os 3 primeiros minutos de forma ininterrupta.

Figura 3 - Captura do chat do Facebook entre a praticante e os pesquisadores.

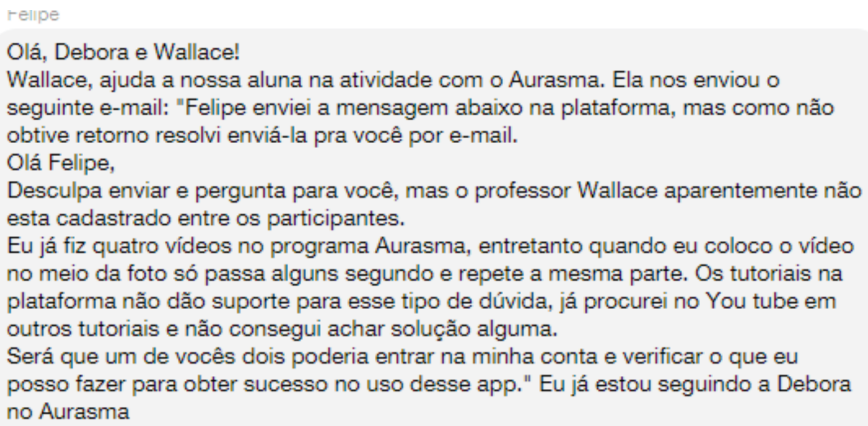

Olá QDebora Ricardo

Me passa por favor o vídeo que você quer colocar no aplicativo

Assim consigo analisar

Fonte - Print do chat do Facebook do pesquisador

Foi nesse momento que Débora tentou adaptar o conteúdo de seu vídeo para imagens fixas e estáticas para tentar se adequar ao que ela achava se tratar de uma "deficiência" do aplicativo. 
Figura 4 - Captura do chat do Facebook entre a praticante e os pesquisadores.

Debora

Achei esse app muito falho para poucos recursos

Acabei de fazer aqui e funcionou perfeitamente

Debora

Foi por lá que eu fiz e pelo celular

tanto no app quanto no site

me passe o vídeo entẫo

s6́ pode ser isso agora

Fonte - Print do chat do Facebook do pesquisador

Ao expressar sua frustração em nosso chat, ela relata essa dificuldade em conseguir realizar sua atividade, e afirma: "Achei esse app muito falho para poucos recursos", revelando sua visão crítica de nossa proposta.

Figura 5 - Captura do chat do Facebook entre a praticante e os pesquisadores.

\footnotetext{
Olá Wallace, como o vídeo mesmo sendo de 3 minutos não esta funcionando nesse programa estou tentando fotos, mas mesmo assim as fotos ficam uma por cima da outra e năo funcionam. Sinceramente năo sei mais o que fazer. Esta acabando o

(1) prazo de entrega e nada deu conseguir fazer a atividade

Na quarta foto ele já disse que não tinha mais espaço até ai tudo bem, mas depois as fotos ficam uma por cima da outra e não funciona. Isso por que eu fazendo no computador descktop por que no celular não funciona nunca.
}

Fonte - Print do chat do Facebook do pesquisador 
Depois de mais algumas tentativas e de perceber que o vídeo ficava estático e que as fotos não estava atendendo a sua expectativa, dispara que se fosse para funcionar desse modo seria "preferível fazer um Power Point”. Nesse registro da percepção de Débora evidenciamos sua representação crítica diante da situação em que se encontrava e que estabeleceu uma nova abordagem daquilo que havíamos concebido como o que deveria ser percebido pelos praticantes da disciplina.

Em nossa relação estabelecida a fim de resolver seu problema, pudemos perceber várias nuances acerca daquilo que estava estabelecido na premissa da disciplina (que era a oportunidade de estabelecer um contexto de App-Learning) e aquilo que estávamos recebendo (da necessidade imediata de aprendizado da competência de mediação de minha parte e a necessidade de criarmos competências de letramento digital aos praticantes.)

Em sua crítica, Débora nos ajudou a transformar o método que estávamos aplicando até então na disciplina, e suas observações resultaram em um novo material tutorial que foi disponibilizado à todos os praticantes da disciplina.

Figura 6 - Captura do chat do Facebook entre a praticante e os pesquisadores.

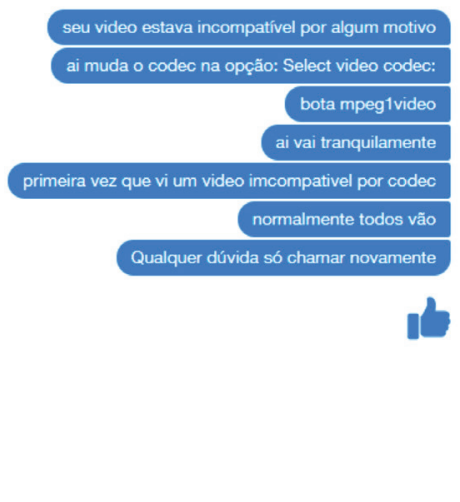

QElisiane Elisa se tiver algum problema me manda o vídeo!

Fonte - Print do chat do Facebook do pesquisador 
Figura 7 - Captura do chat do Facebook entre a praticante e os pesquisadores.

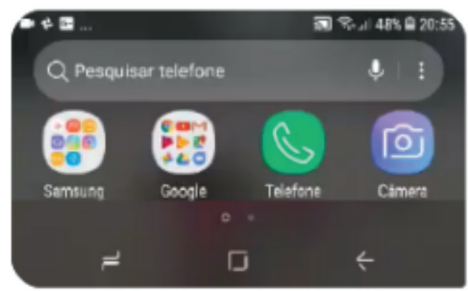

Usem o aurasma Studio no computador para criar as auras e depois usem o celular para visualizar

Vou tentar amanhã fazer isso funciona. Muito obrigada pela ajuda e desculpa ter the

incomodado no domingo

Vou ver se consigo agora. Qualquer coisa entro em contato com vcs meninas.

Obrigada Wallace!

Fonte - Print do chat do Facebook do pesquisador

A terceira e última forma de manifestação de autoria, a autoria criadora, pode ser observada em diversas produções dos praticantes da disciplina, mas em nenhuma delas pudemos evidenciar maior aspecto criativo do que o encontrado no trabalho do grupo que tornou acessível a visita ao Museu Imperial de Petrópolis.

De diversas produções postadas nos fóruns da disciplina, encontramos um caso que não somente autoriza-se do uso da realidade aumentada na construção de um contexto formativo, como 
também inova na perspectiva de tornar a nossa própria realidade acessível a uma comunidade especial de pessoas que, em 2010 reunia cerca de 360 milhões de pessoas no mundo e 9,7 milhões de pessoas somente no Brasil.

A praticante Leticia Klôh, revela em sua postagem no fórum do Moodle, que sua inspiração para produzir a atividade nasce da sua relação com a comunidade surda petropolitana e com a educação dos mesmos. Tomando a proposta de criar uma atividade formativa em um espaço da cidade que se utilizasse da perspectiva da Realidade Aumentada proporcionada pelo aplicativo Aurasma, ela cria uma interação física com o espaço do Museu Imperial.

O Museu Imperial, popularmente conhecido como Palácio Imperial, possui o principal acervo do país relativo ao império brasileiro e está localizado no centro histórico da cidade de Petrópolis, no estado do Rio de Janeiro. Como prova de conceito ela escolhe esse museu pela sua importância histórico-cultural e por não ter encontrado, em sua visita, nenhuma forma de experiência que fizesse com que o surdo se sentisse bem-vindo.

Atendendo a nossa premissa e ao problema identificado por ela e seu grupo, não somente utilizam-se do aplicativo proposto na realização atividade da disciplina, como também inovam, fazendo uso de uma série de outros aplicativos, alguns desconhecidos até mesmo por nós, destacando-se dentre eles um que é capaz de traduzir o texto escrito na língua portuguesa para sua representação gestual correspondente na Língua Brasileira de Sinais.

No aplicativo, Leticia digitou uma mensagem de boas-vindas para os surdos explicando um pouco da história do museu, suas principais obras e uma breve explicação de sua relevância para a comunidade petropolitana. Após digitar a mensagem ela pressiona um ícone no aplicativo que processa todo o texto digitado e devolve na tela uma interpretação 3D em Libras. 
Figura 8 - Captura do vídeo ${ }^{6}$ onde a praticante explica o processo de produção da atividade.

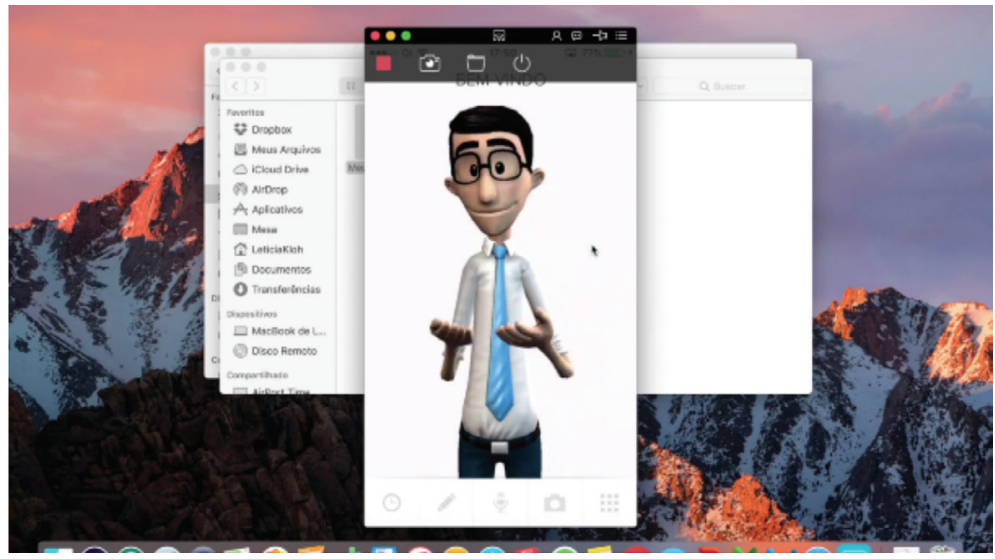

Fonte - Print do vídeo postado no YouTube da disciplina

Em sua proposta, Leticia intenciona portanto, que ao visitarem o Museu Imperial, os surdos possam utilizar o aplicativo Aurasma para serem recepcionados pelo avatar de Hugo. Enquanto caminham pelos ambientes do museu, eles podem aprender e interagir com cada uma das obras expostas da mesma forma autônoma que é verificada através da experiência vivenciada pela grande maioria da comunidade ouvinte. Tendo em vista que cerca de $80 \%$ dos surdos tem dificuldade em ler e escrever a língua escrita de seu país, devido ao seu método de percepção da linguagem ser dar de forma extremamente visual, é um fato verificado que a maior parte deles depende exclusivamente da Língua de Sinais para se comunicar e obter acesso a informação.

Para melhor compreensão, convidamos a você, nosso tão estimado leitor, a experimentar na prática a produção de autoria criativa de Leticia Klôh e seu grupo.

6 O vídeo pode ser acessado na sua íntegra acessando o qr code disponibilizado na captura ou através do link:http://bit.ly/aurasmasurdos 
Para isso são necessários os seguintes passos:

1. Instale o aplicativo Aurasma (ou HP Reveal, nome que recebeu após ter sido comprado pela Hewlett-Packard HP) pelo link ${ }^{7}$ disponível, buscando a versão disponível para o sistema operacional do seu smartphone.

2. Abra o aplicativo e crie a sua conta.

3. Acesse o $\operatorname{link}^{8}$ da aura criada por Leticia (ou aponte para o qrcode abaixo) e clique para seguir suas auras no aplicativo.

4. Abra a câmera do aplicativo e aponte para a imagem abaixo, você deve ser capaz de ver Hugo, o intérprete do Hand Talk fazendo sua apresentação.

Figura 9 - Imagem disparadora da interação no Aurasma criada por Leticia

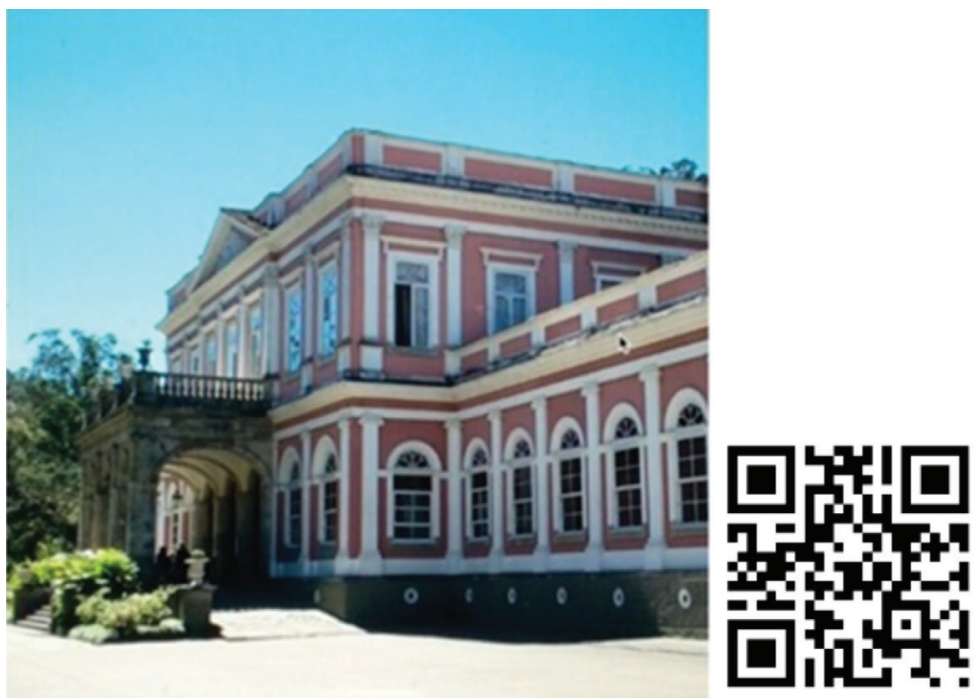

Fonte - Elaborado pelo autor

Link para download do Aurasma: https://studio.hpreveal.com/landing Link para seguir Leticia no Aurasma: http://auras.ma/s/uWIcr 


\section{Conclusão}

Ser um autor em tempos de App-Learning, é muito mais que produzir contextos formativos utilizando-se de aplicativos de dispositivos móveis, pois esse processo deve ser parte de um novo fazer pedagógico que lança mão de outras lógicas e aprendizagens, descobertas e autorias de quem realmente está imerso na cultura, ou seja, da cibercultura. (SANTOS, 2017, pg. 12).

Seguindo essa lógica, Backes (2002, pg. 84) afirma que o desenvolvimento do processo de autoria na formação do educador, por meio da utilização de tecnologias digitais, como a perspectiva de App-Learning, promove o ato de ativar, criar e impulsionar a construção do conhecimento e saberes docentes para, então, a construção de uma prática pedagógica própria e significativa para os estudantes.

Assim sendo, a formação de docentes que sejam também autores de suas próprias práticas precisa partir do cenário contemporâneo social para atravessar a estrutura universitária, proporcionando assim momentos em que sejamos transformados por esse novo olhar que nos permite viajar em busca de encontrar em nosso próprio fazer a produção de sentidos.

Esse foi o dilema que originou e guiou nossa pesquisa, e é na tentativa de entender esse contexto que movemos esse trabalho, entendendo que somente a vivência com os praticantes e o mergulho em suas criações podem nos ajudar a definir caminhos para construir essa realidade.

Assim encerramos nossa narrativa acerca de toda a autoria produzida em nossa pesquisa, acreditando que ao vivenciarmos cada uma de suas etapas, possibilitamos a manifestação desses movimentos nas produções não somente na prática desses educadores em formação, mas também em mim mesmo, que por ter sido formado e transformado com eles, já almejo inovar em minha autoria em novos vôos. 


\section{Referências}

BACKES, Luciana. As manifestações da autoria na formação do educador em espaços digitais virtuais. Revista de Educação, Ciência e Cultura, v. 17, n. 2, jul./dez. 2012. Disponível em: http://bit.ly/autoriabackes. Acesso em Novembro de 2017.

CERTEAU, Michel de. A invenção do cotidiano: 1. artes de fazer. Petrópolis, RJ: Vozes, 1994.

CHARTIER, Roger. O Que é um Autor? Revisão de uma Genealogia. São Carlos: EDUFSCar, 2012.

CREATIVE COMMONS. O que é Creative Commons? Acessado em: 26/09/2018. Disponível em: http://bit.ly/crcommons

MIRANDA, Antonio; SIMEAO, Elmira and MUELLER, Suzana. Autoria Coletiva, Autoria

Ontológica e Intertextualidade na Ciência: Aspectos Interdisciplinares e Tecnológicos. 2007, vol.36, n.2, pp.35-45. Disponível em http://bit.ly/2MmOE9m. Acesso em Maio de 2018

PASSARELLI, Brasilina. Capital Social na Pós-Graduação em Ciências da Comunicação: um estudo de caso do portal CRIANDO COMUNIDADES VIRTUAIS DE APRENDIZAGEM E DE PRÁTICA. Prisma.com, n. 5, 2007

Disponível em: http://bit.ly/2nwxnfV. Acesso em Fevereiro de 2018

SANTAELLA, Lucia. App-learning e a imaginação criativa a serviço da educação [Prefácio]. In: COUTO, Edvaldo; PORTO, Cristiane; SANTOS, Edmea (Org.). App -learning: experiências de pesquisa e formação. Salvador: EDUFBA, 2016.

SANTOS, Edméa. Pesquisa-formação na cibercultura. Portugal: Whitebooks, 2014.

Entrevista com Edméa Oliveira dos Santos. Teccogs: Revista Digital de Tecnologias Cognitivas, TIDD | PUCSP, São Paulo, n. 16, p. 10-28, jul-dez. 2017. Entrevista concedida a Werley Carlos de Oliveira

Tecnologia pode auxiliar a interdisciplinaridade em sala de aula. Acessado em: 26/09/2018. Disponível em: http://bit.ly/aprendebrasil

. PONTE, Felipe. ROSSINI, Tatiana. Autoria em rede: uma prática pedagógica emergente. Rev. Diálogo Educ., Curitiba, v. 15, n. 45, p. 515-536, maio/ago. 2015 Disponível em: http:/ / bit.ly/2MGjneJ. Acesso em Julho de 2018. 


\section{WALLACE CARRIÇO DE ALMEIDA}

CV LATTES: http://lattes.cnpq.br/6246998456973189 ORCID: https://orcid. org/0000-0003-4593-554X

E-mail: wallace.almeida@me.com telefone: (21) 96986-7141

Endereço: Rua Jorge da Silva, 69 - Apto 101, Santa Teresa, Rio de Janeiro, RJ, CEP: 20251-180

\section{EDMÉA OLIVEIRA DOS SANTOS}

CV LATTES: http://lattes.cnpq.br/4023554724278836 ORCID: http://orcid. org/0000-0003-4978-9818

E-mail: edmeabaiana@gmail.com telefone: (21) 9962-12804

Endereço: Av Nossa Senhora de Copacabana, 2/101, Leme, Rio de Janeiro, RJ, CEP: 22010-121 